\title{
Structure-Function Relationship of Rhamnan Sulfate Isolated from Commercially Cultured Edible Green Seaweed, Monostroma nitidum
}

\author{
Masakuni Tako ${ }^{1,2,{ }^{*} \text {, Yoichi Yamashiro }}{ }^{1}$, Takeshi Teruya ${ }^{1}$, Shuntoku Uechi ${ }^{1}$ \\ ${ }^{1}$ Department of Subtropical Bioscience and Biotechnology, Faculty of Agriculture, University of the Ryukyus, Okinawa, Japan \\ ${ }^{2}$ Health and Longevity Research Laboratory, University of the Ryukyus, Okinawa, Japan
}

\section{Email address:}

tako@agr.u-ryukyu.ac.jp (M. Tako)

*Corresponding author

\section{To cite this article:}

Masakuni Tako, Yoichi Yamashiro, Takeshi Teruya, Shuntoku Uechi. Structure-Function Relationship of Rhamnan Sulfate Isolated from Commercially Cultured Edible Green Seaweed, Monostroma nitidum. American Journal of Applied Chemistry. Vol. 5, No. 2, 2017 , pp. 38-44. doi: 10.11648/j.ajac.20170502.13

Received: January 26, 2017; Accepted: April 19, 2017; Published: May 23, 2017

\begin{abstract}
The green seaweed, Monostroma nitidum, is widespread in Japan. In Okinawa Prefecture, production of seaweed is performed using culture-nets that are seeded artificially. The annual production of the algae in Okinawa was approximately $100 \mathrm{t}$ in 2016. Recently, because Monostroma nitidum is used in salads, soups and other items, its utilization in the food industry increased. The algae contain a soluble polysaccharide, rhamnan sulfate. To estimate the applicability of a rhamnan sulfate as a food additive or non-food additives, we investigated the rheological properties of the polymer that was isolated from commercially cultured Monostroma nitidum using a rheogoniometer. A soft gelation occurred at a concentration of $4.0 \%$, and the elastic modulus stayed at a constant value after the temperature to $50^{\circ} \mathrm{C}$, which was estimated to be a transition temperature, then decreased rapidly with further increase in temperature. Although a small decrease in elastic modulus was observed with the addition of urea $(4.0 \mathrm{M})$, it remained constant with an increase in temperature up to $60^{\circ} \mathrm{C}$, and then decreased. An increase in the elastic modulus was observed in a $0.05 \mathrm{M} \mathrm{NaOH}$ solution and soft gelation occurred. The elastic modulus remained large during the increase in temperature even at $90^{\circ} \mathrm{C}$. A soft gelation also occurred when rhamnan sulfate was dissolved in a Tris buffer $(\mathrm{pH}$ 8.0) solution. The possible mode of intra- and intermolecular associations within and between rhamnan sulfate molecules were discussed.
\end{abstract}

Keywords: Green Seaweed, Monostroma nitidum, Rhamnan Sulfate, Structure-Function Relationship, Intra- and Intermolecular Associations, Gelation Mechanism

\section{Introduction}

Polysaccharides derived from microorganisms, plants and animals are used as thickening, stabilizing and gelling agents. Each polysaccharide has special properties that result from its individual molecular structure. We discussed the structure-function relationship from the view point of rheological characteristics of the polysaccharides and proposed the gelation mechanism of $\kappa$-carrageenan [1-3], i-carrageenan [4, 5], agarose (agar) [6] gellan gum [7], amylose [8], curdlan [9], alginic acid [10, 11], rice starch [12-14], potato starch [15], wheat starch [16, 17], deacetylated rhamsan gum [18] and native gellan gum [19] at the molecular level in aqueous solutions. The hydroxyl, hemiacetal and/or methyl groups of sugar residues participated in intra- and/or intermolecular associations with hydrogen bonding and van der Waals forces of attraction in neutral polysaccharides solutions, such as agarose, amylose, curdlan, gellan gum, deacetylated rhamsan gum and starches. The sulfate and carboxyl groups of the sugar residues of some acidic polysaccharides, such as $\kappa$-carrageenan, 1 -carrageenan, gellan gum, alginic acid, deacetylated rhamsan gum and native gellan gum, might also participate in intra- and/or intermolecular associations through univalent or divalent 
cations with ionic bonding or electrostatic forces of attraction.

We also proposed a co-gelation mechanism between xanthan and galactomannan (locust-bean gum [20-23], guar gum [24], tara-bean gum [25], Leuchaena gum [26], and Leonix gum [27]), and between xanthan and glucomannan [28].

Furthermore, we proposed intramolecular associations for the gellan family of polysaccharides, welan [29], rhamsan [30], S-657 [31], S-88 [32] and S-198 [33] gum where methyl groups of the L-rhamnosyl residue plays an important role, leading to their thermal stability in aqueous solutions.

Consequently, we realized, in principle, that there are some basic rules for in gel-formation processes including water molecules and polysaccharides at the molecular level $[34,35]$ The gelation occurs in the formation of intramolecular association to make polymer molecule rigid, then intermolecular associations take place in aqueous solutions. We also reported the principle of amylose, amylopectin and starch gelatinization as well as retrogradation including water molecules at the molecular level [36].

Some edible green seaweeds as well as brown and red ones are grown in Okinawa Islands. We isolated rhamnan sulfate (Ulvan) from an edible green seaweed, Ulva pertusa, and proposed chemical structure (heptasaccharide repeating units) as shown in Figure 1 [37] which was revised a little because oligosaccharides, $\quad \beta$-D-glucuronic acid- $(1 \rightarrow 4)-\alpha$-L-rhamnopyranose- $(1 \rightarrow$ and $\alpha$-L-idulonic acid- $(1 \rightarrow 4)--\alpha$-L-rhamnopyranose- $(1 \rightarrow$ were identified in published papers [38-40]. The ulvan consisted of 1,4-linked $\alpha$-L-rhamnopyranosyl (3 molar) and D-xylopyranosyl ( 1 mol.), and 1,3-linked $\alpha$-L-rhamnopyranosyl (1 mol.) residues on the main chains. Terminal D-glucuronpyranosyl (1.5 mol.) and L-idulonopyranosyl $(0.5 \mathrm{~mol}$.) residues were attached at C-2 and/or C-4 of L-rhamnosyl residues on the main chains. The sulfate groups were attached at C-2 and C-3 of the L-rhamnopyranosyl residue as well as $\mathrm{C}-3$ of the D-xylopyranosyl residues. Ulvan is known to exhibit gel [39, 40].

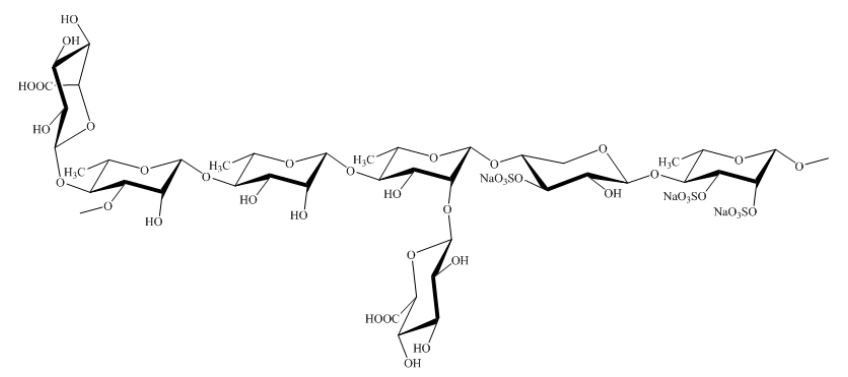

Figure 1. Chemical structure of rhamnan sulfate (Ulvan) isolated from Ulva pertusa.

The green seaweed, Monostroma nitidum, is widespread in nature between Korea, Japan and China. In Okinawa Prefecture, Japan, the production of the seaweed is performed using culture-nets that are seeded artificially. The annual production of the alga in Okinawa was approximately $100 \mathrm{t}$ in 2016. Recently, because M. nitidum is used in salads, soups and some other items, its utilization in the food industry has increased. We reported the chemical structure of rhamnan sulfate (octa-saccharide repeating units) that was isolated from commercially cultured an edible green seaweed, $M$. nitidum [41]. The rhamnan sulfate consists of 1,3-linked $\alpha$-L-rhamnopyranosyl residues on the main chain, a part of which has $\beta$-D-glucuropyranosyl-( $1 \rightarrow 2)$ - $\alpha$-L-rhamnopyranosyl-( $(1 \rightarrow 2)-$ $\alpha$-L-rhamnopyranosyl trisaccharide side-chains at the C-2 position on the main-chain. The sulfate groups are substituted at the $\mathrm{C}-4$ position of the L-rhamnopyranosyl residues on the main-chain, and at C-3 position on the side-chains, as shown in Figure 2.

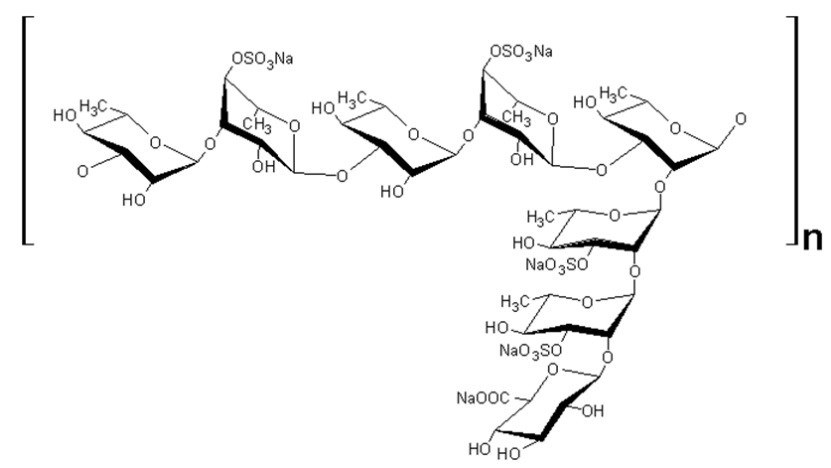

Figure 2. Chemical structure of rhamnan sulfate isolated from Monostroma nitidum.

To estimate the applicability of rhamnan sulfate as food a additives or non-food additives, we report the rheological characteristics of the polysaccharide. Its structure-function relationship was analyzed with respect to the association characteristics in aqueous solutions.

\section{Materials and Methods}

\subsection{Materials}

Monostroma nitidum, which was commercially cultured on nets $(1.5 \times 20 \mathrm{~m})$ at sea off the central part of Okinawa Island (Kitanakagusuku Village), was used in this study.

\subsection{Preparation of Rhamnan Sulfate}

An air-dried seaweed sample (20 g) was suspended in 0.05 $\mathrm{M} \mathrm{HCl}$ and stirred at $60^{\circ} \mathrm{C}$ for $3 \mathrm{~h}$ to extract rhamnan sulfate. The extract was then centrifuged at $13,000 \mathrm{~g}$ for $20 \mathrm{~min}$, and the supernatant was filtered through Celite 545. The filtrate was neutralized with $0.5 \mathrm{M} \mathrm{NaOH}$ and then precipitated by the addition of 2 volumes of ethanol. The precipitate was dried in vacuo [41].

The crude polysaccharide was dissolved in distilled water and the solution was passed through Celite 545. The filtrate was deionized by passing through a cation exchange column composed of Amberlite 120 $\mathrm{A} \mathrm{H}^{+}$(Organo, Japan). The rhamnan sulfate solution was neutralized with a $0.05 \mathrm{M} \mathrm{NaOH}$ solution. The solution was subsequently precipitated by the addition of 2 volumes of ethanol. The precipitate was dried in vacuo [41]. 


\subsection{Determination of Total Carbohydrate, Uronic Acid and Sulfuric Acid of Rhamnan Sulfate}

The composition of the total carbohydrate and uronic acid was determined by the phenol-sulfuric acid method [42] and the carbazole-sulfuric acid method [43] using L-rhamnose and D-glucuronic acid as standards, respectively. Sulfuric acid was determined by the turbid-metric method described by Dodgson and Price [44].

\subsection{Molecular Mass Determination of Rhamnan Sulfate}

The molecular mass of rhamnan sulfate $(1 \mathrm{mg} / \mathrm{mL})$ was determined by high-performance liquid chromatography (HPLC), using an LC-6A chromatograph (Shimadzu, Kyoto Japan) on a TSK-gel GMPW column $(7.8 \times 200 \mathrm{~mm}$, Tosoh Corporation, Tokyo, Japan). The HPLC analysis was performed at a flow rate of $0.3 \mathrm{~mL} / \mathrm{min}$ with refractive index detection (RID-6A, Shimadzu) at room temperature. The column was conditioned with $0.15 \mathrm{M}$ sodium chloride in 0.05 $\mathrm{M}$ sodium phosphate buffer ( $\mathrm{pH} 7.2$ ), and elution was conducted with the same buffer. Standard pullulans (Showa Denko Co. Ltd., Tokyo, Japan) including P-800 (molecular mass, $\quad 810 \mathrm{kDa}), \quad$ P-400 (400kDa), P-200 (220kD), P-100(110kDa) and P-80 (80kDa) were used as molecular mass markers.

\subsection{Rheological Measurements}

An aqueous solution was obtained by stirring rhamnan sulfate for $30 \mathrm{~min}$ at room temperature. The viscosity at various shear rates $\left(1.19-95.03 \mathrm{~s}^{-1}\right)$ and the dynamic viscoelasticity at a fixed frequency (3.77 $\left.\mathrm{rads}^{-1}\right)$ were determined with a rheogoniometer (Iwamoto Seisakusho Co., Ltd, Japan) consisting of a coaxial cylinder $(1.8 \mathrm{~cm}$ diam.) with a rotating outer cylinder $(2.2 \mathrm{~cm}$ diam.). The temperature of the sample was controlled by circulating oil from a thermo-cool instrument (LCH-130F, Toyo Co., Ltd, Japan), over the temperature range of 0 to $90^{\circ} \mathrm{C}$ that was increased at a stepwise rate of $1^{\circ} \mathrm{C} \min ^{-1}$. Shear rate $(\gamma)$, shear stress $(\tau)$, and viscosity $(\eta)$ were calculated with the equation of Margules [45]. The dynamic viscosity ( $\eta$ ') and elastic modulus (G') were calculated by modification of Markovitz's equation [46]. The loss tangent $(\tan \delta)$ was calculated from the relationship, $\tan \delta=\mathrm{G} " / \mathrm{G}$, where $\mathrm{G}$, $=\omega \eta$ ' is the loss modulus, and $\omega$ is the angular velocity of the outer cylinder.

\section{Results}

\subsection{Chemical Characteristics and Molecular Mass of Rhamnan Sulfate}

The yield of rhamnan sulfate from commercially cultured $M$. nitidum was $21.7 \%$ and $5.4 \%(\mathrm{~W} / \mathrm{W})$ on the basis of dried and wet algae. The total carbohydrate, D-glucuronic acid and sulfate contents of the rhamnan sulfate were estimated as $64.1 \%, 13.5 \%$ and $21.2 \%$, respectively. The molecular mass of rhamnan sulfate was $600 \mathrm{kDa}$.

\subsection{Flow Properties}

The flow curve at a concentration of $2.0 \%$ approximated shear-thinning behavior and increased gradually with increase in shear force (not shown in Figure). The flow curve of the $3.0 \%$ solution showed plastic behavior, the yield value of which was estimated to be $0.5 \mathrm{~Pa}$, which increased gradually with an increase in shear force. For the $4.0 \%$ solution, the flow curve also showed plastic behavior, the yield value of which was $0.8 \mathrm{~Pa}$, and increased linearly up to $9.5 \mathrm{~s}$, then increased gradually. The yield value indicates that a secondary association (intra-and/or intermolecular) is involved in rhamnan sulfate molecules at high concentrations (3 and 4\%) in aqueous solution [1-19].

Logarithmic plots of shear rate and shear stress for the rhamnan sulfate, as shown in Figure 3, showed a refraction point at concentration of 2,3 , and $4 \%$. Such refraction point was also observed for locust-bean gum (single side chain) [47], guar gum (single side chain) [47] and xanthan gum (trisaccharide side chain) [48] where side chains of those polysaccharides contributed to entanglements of the molecular chains under shearing force in aqueous solutions. The results suggested that the rhamnan sulfate involved side chains as in locust bean gum, guar gum and xanthan gum. The result supports the chemical structure of the rhamnan sulfate (Figure 2) as reported by the authors [41].

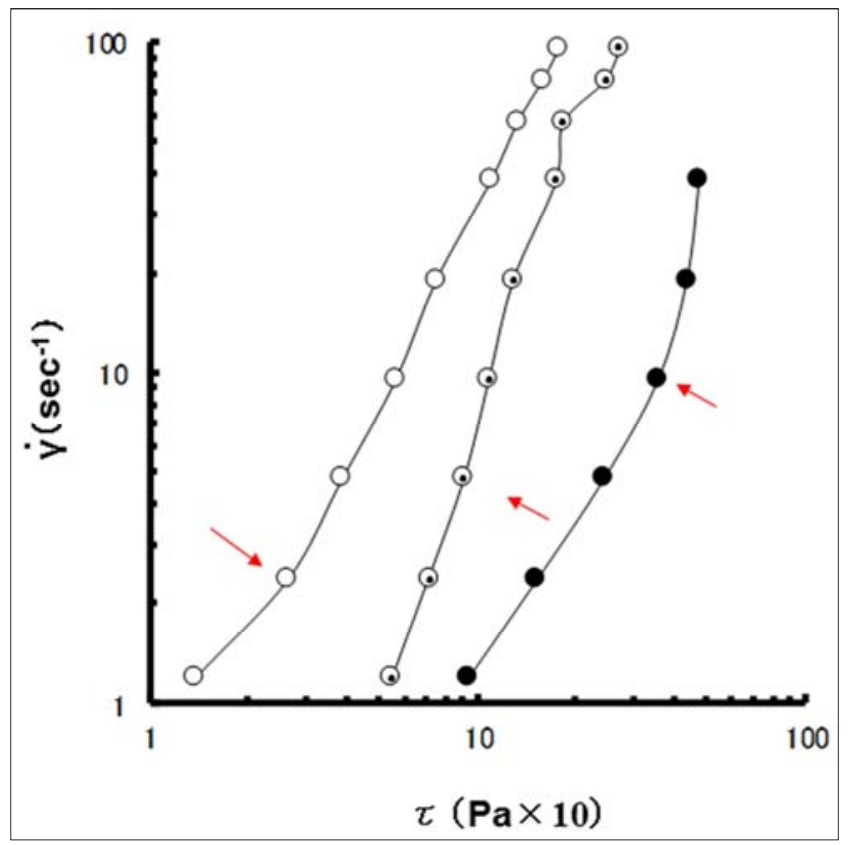

Figure 3. Logarithmic plot of flow curves of rhamnan sulfate from M. nitidum at various concentrations at $25^{\circ} \mathrm{C}$.

$\rightarrow$, Refraction point

Concentration: $\circ, 2 \% ; \odot, 3 \% ; \bullet, 4 \%$.

\subsection{Elastic Modulus}

The elastic modulus of rhamnan sulfate decreased gradually with increasing temperature to $30^{\circ} \mathrm{C}$, which was estimated to be a transition temperature, however, it stayed 
constant value with further increase in temperature up to $45^{\circ} \mathrm{C}$, and then decreased in the $2.0 \%$ solution (not shown in Figure). A large elastic modulus was observed in the $3.0 \%$ solution at low temperature $\left(0^{\circ} \mathrm{C}\right)$ and remained constant with increasing temperature to $45^{\circ} \mathrm{C}$, which was estimated to be a transition temperature, and then decreased rapidly. A very large elastic modulus was observed in the $4.0 \%$ solution and gelation occurred at low temperature $\left(0^{\circ} \mathrm{C}\right)$. The elastic modulus remained constant with increasing temperature to $45^{\circ} \mathrm{C}$, which was estimated to be a transition temperature, and then decreased rapidly. On the other hand, the $\tan \delta$ value was large (1.2) at a low temperature $\left(0^{\circ} \mathrm{C}\right)$, increased gradually with increasing temperature to $15^{\circ} \mathrm{C}$, and then remained constant. After reaching $50^{\circ} \mathrm{C}$, the value slightly decreased in the $2.0 \%$ solution. The tan $\delta$ decreased to 0.36 with increasing concentration to $3.0 \%$ at low temperature $\left(0^{\circ} \mathrm{C}\right)$ and remained constant with increasing temperature up to $40^{\circ} \mathrm{C}$, which was estimated to be a transition temperature, then slightly decreased. A smaller $\tan \delta$ was observed when the concentration increased to $4.0 \%(0.25)$. The value remained constant up to $45^{\circ} \mathrm{C}$, which was estimated to be a transition temperature, and then increased. The transition temperature is the temperature above which the secondary association dissociates. The results indicate that rhamnan sulfate molecules have a thermostable characteristic in aqueous solution as in gellan family of polysaccharides [29-33].

As shown in Figure 4, a small decrease in the elastic modulus was observed upon addition of $4.0 \mathrm{M}$ urea $[6,8,9]$ to the $4.0 \%$ aqueous solution of rhamnan sulfate, but the elastic modulus remained constant with increasing temperature to $60^{\circ} \mathrm{C}$, which was estimated to be a transition temperature, and then decreased rapidly. The tan $\delta$ shifted higher than in aqueous solution (0.25) upon addition of urea (0.37) at low temperature $\left(0^{\circ} \mathrm{C}\right)$ and increased with increasing temperature to $10^{\circ} \mathrm{C}$, but stayed constant until $60^{\circ} \mathrm{C}$, which was estimated to be a transition temperature. The $\tan \delta$ then increased with further increases in temperature. A small decrease in the elastic modulus at low temperature $\left(0^{\circ} \mathrm{C}\right)$ indicates that hydrogen bonding is involved in rhamnan sulfate molecules in aqueous solution and indicated that another secondary association was involved because the elastic modulus was large and remained constant up to the transition temperature $\left(60^{\circ} \mathrm{C}\right)$ in a $4.0 \mathrm{M}$ urea solution. Another secondary association dissociated rapidly above the transition temperature. The result suggests that van der Waals forces are co-involved in addition to hydrogen bonding [7, 8, 19, 29].

A very large elastic modulus approximately 10 times that of the aqueous solution $(4.0 \%)$ was observed when rhamnan sulfate was dissolved in $0.05 \mathrm{M} \mathrm{NaOH}$ solution [12-17] at a low temperature $\left(0^{\circ} \mathrm{C}\right)$ and soft-gel occurred as shown in Figure 5. The elastic modulus remained large during the increase in temperature even at $90^{\circ} \mathrm{C}$. However, $\tan \delta$ value was large even at low temperature (1.0), slightly increased with increasing temperature to $80^{\circ} \mathrm{C}$, and then decreased. The result indicates that soft gelation takes place even after becoming free from hydrogen bonding, because $\mathrm{NaOH}$ is also a hydrogen bonding breaker [12-17]. The result suggests that van der Waals forces of attraction was involved in the intraand intermolecular association in aqueous solution. The increase in the $\tan \delta$ value may be caused by association between trisaccharide side-chains on different molecules as in Ca-salt of xanthan molecules [49]. The result suggests that $\mathrm{Na}^{+}$bridges between sulfate groups of long side chains were built up with ionic bonding and electrostatic forces of attraction at high concentration in alkaline solution.

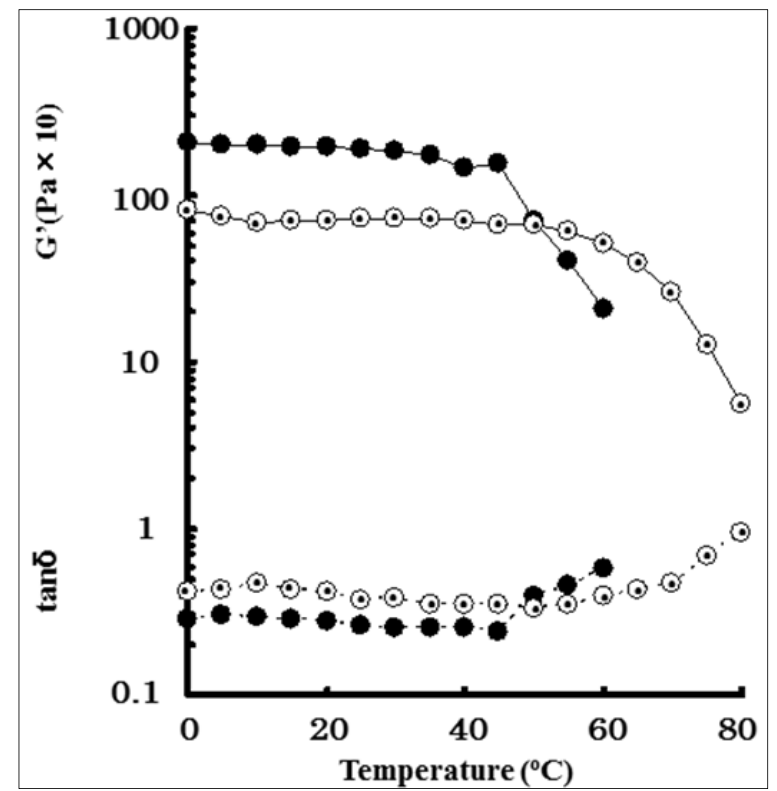

Figure 4. Effect of temperature on the elastic modulus of rhamnan sulfate (concentration, $4.0 \%$; •) from M. nitidum with addition of $4.0 M$ urea $(\odot)$.

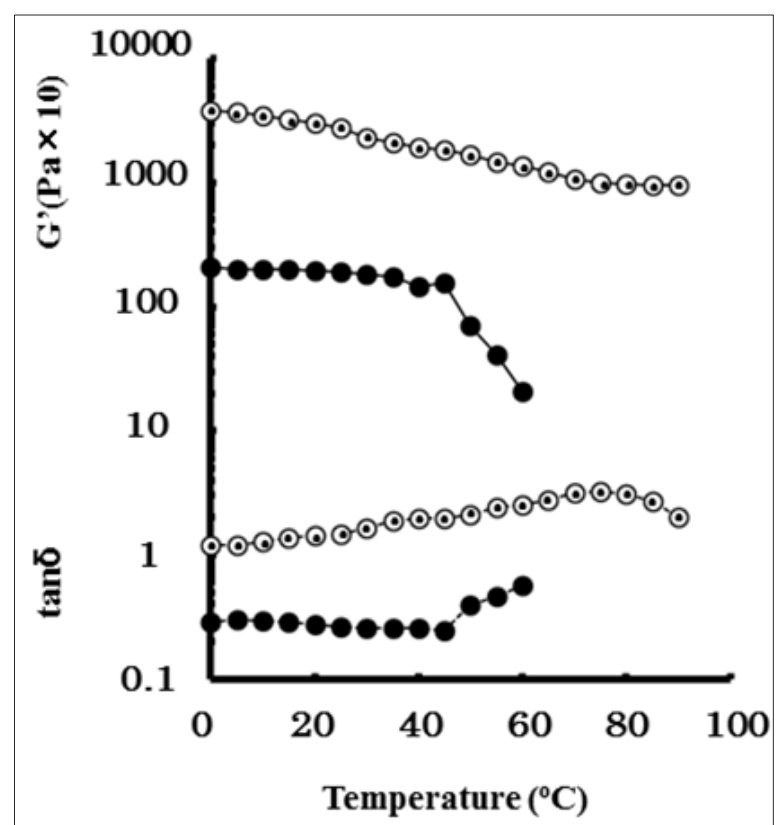

Figure 5. Effect of temperature on the elastic modulus of rhamnan sulfate $(4.0 \%$, •) from $\mathrm{M}$. nitidum in alkanline solution $(0.05 \mathrm{M}-\mathrm{NaOH}, \odot)$.

Figure 6 shows the effect of temperature on the elastic modulus and $\tan \delta$ of the rhamnan sulfate at $3.0 \%$ in Tris- $\mathrm{HCl}$ (10 and $20 \mathrm{mM}$ ) buffer ( $\mathrm{pH} 8.0$ ) solutions. Very large elastic moduli, approximately 20-30 times of those of aqueous 
solution, were observed in both buffer solutions, and soft gelation occurred. The elastic moduli were constant with increase in temperature up to $60^{\circ} \mathrm{C}$, which was estimated to be a transition temperature, and then decreased rapidly. The $\tan \delta$ was larger, 1.0 and 1.6, in 10 and $20 \mathrm{mM}$ buffer solutions, than in aqueous solution $(0.36)$ at low temperature $\left(0^{\circ} \mathrm{C}\right)$, increased with increasing temperature up to $45^{\circ} \mathrm{C}$, and then decreased with further increases in temperature. The result suggests that rhamnan sulfate molecules associate with 2-amino-2-(hydroxymethyl) propane-1,3-diol (Tris) with ionic bonding and electrostatic forces of attraction between the side-chains of the sulfate groups on the different molecules of the rhamnan sulfate.

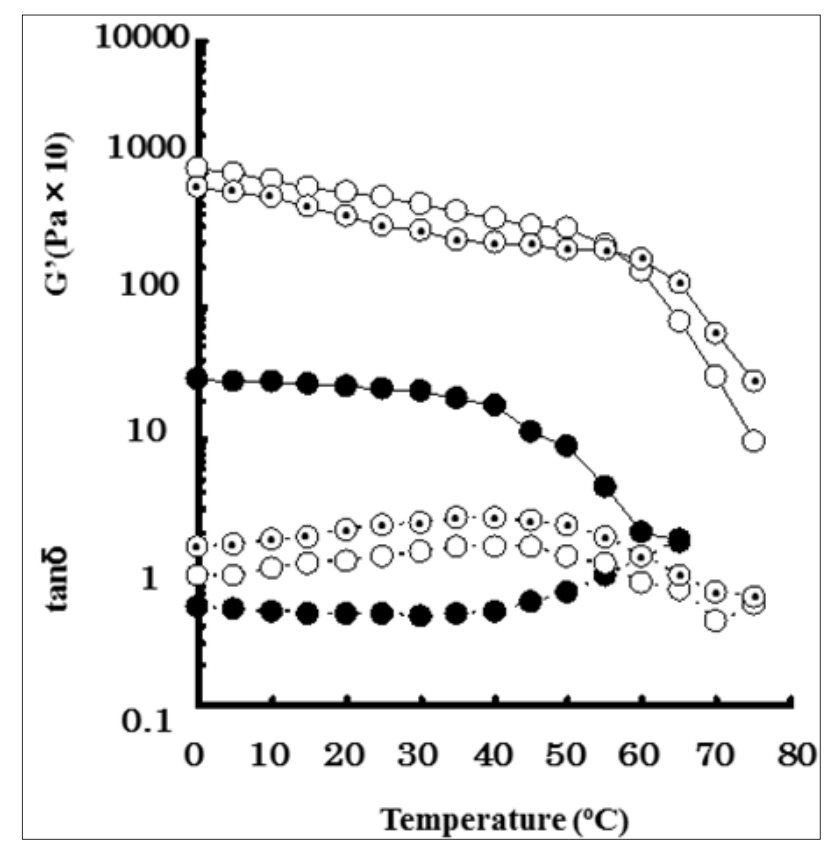

Figure 6. Effect of temperature on the elastic modulus of rhamnan sulfate from M. nitidum (3\%; O) in Tris-HCI buffer $(10 \mathrm{mM} ; \odot$ and 20mM; 0 , pH8.0).

\section{Discussion}

The L-rhamnosyl residue plays a dominant role in gel-formation and thermostable processes in native [19] and deacylated [7] gellan gum, and native [30] and deacetylated rhamsan [18] gum solutions. Although the methyl groups of the L-rhamnosyl residues co-exist in ${ }^{1} \mathrm{C}_{4}$ and ${ }^{4} \mathrm{C}_{1}$ pyranose-ring conformations in native gellan and rhamsan gum molecules, resulting in soft-gel formation or thermal stability, they showed stiff and brittle gels on deacylation or deacetylation by treatment with a $0.2 \mathrm{M} \mathrm{NaOH}$ solution, where almost all of the L-rhamnosyl residues existed the ${ }^{4} \mathrm{C}_{1}$ pyranose-ring conformation [7, 18, 19]. Such a flexible conformational change might also occur in the rhamnan sulfate molecules in an alkaline solution.

A soft gelation occurred at low temperature $\left(0^{\circ} \mathrm{C}\right)$ at a concentration of $4.0 \%$ in the rhamnan sulfate aqueous solution. Thus, we proposed possible mode of intra- and intermolecular associations. Intramolecular hydrogen bonding may take place between the $\mathrm{OH}-4$ of the L-rhamnosyl residue which may adopt the ${ }^{1} \mathrm{C}_{4}$ pyranose-ring conformation and adjacent hemiacetal oxygen atom of the L-rhamnosyl residue, which may adopt the ${ }^{4} \mathrm{C}_{1}$ pyranose-ring conformation within molecules to make them rigid. An intermolecular van der Waals forces of attraction may take place between the methyl group adopting the axial orientation of the L-rhamnosyl residue and the hemiacetal oxygen atom of the L-rhamnosyl residue (on the main-chain and/or side-chain) on different molecules as in deacylated gellan [7], deacetylated rhamsan [18] and native gellan [19] gum molecules.

A soft gelation also occurred in alkaline $(0.05 \mathrm{M} \mathrm{NaOH})$ solution, even after becoming free from intramolecular hydrogen bonding which may be caused by a conformational change, $\quad{ }^{1} \mathrm{C}_{4} \quad$ pyranose-ring to ${ }^{4} \mathrm{C}_{1}$.pyranose-ring conformational change on the L-rhamnosyl residues [18,19], where the $\mathrm{OH}-4$ and methyl (C-6) groups adopted the axial orientation. Consequently, intermolecular $\mathrm{Na}^{+}$bridges between sulfate groups of the trisaccharide side-chains with ionic bonding and electrostatic forces of attraction on different molecules may take place resulting in gel-formation, because $\tan \delta$ values showed high values [48].

In Tris- $\mathrm{HCl}$ buffer solutions, the sulfate groups of rhamnan sulfate molecules associated with amino groups $\left(\mathrm{NH}_{2}\right)$ through ionic bonding and electrostatic forces of attraction between the sulfate groups of the trisaccharide side-chains on different molecules, resulting in gel-formation, because $\tan \delta$ values also increased in Tris-HCl buffer [48].

\section{Conclusion}

The $\alpha$-1,3-linked rhamnan sulfate from Monostroma nitidum gelled in the presence of Tris (2-amino-2-hydroxymethyl-propane)- $\mathrm{HCl}$, but $\alpha$-1,4-linked ulvan from Ulva pertusa made a gel via $\mathrm{Ca}^{+2}$ cation $[43,44]$. Those different results are caused by molecular structure as shown in Figure 2 and 1.

Thus, rhamnan sulfate from Monostroma nitidum has unique gelling characteristics. The results and discussion suggests that rhamnan sulfate can be used in foods, cosmetics and some other industries as a gelling, thickening, stabilizing and water-holding agents. Finally, rheological analysis is the most useful method to discuss the structure-function relationship of polysaccharides at the molecular level in aqueous solutions.

\section{Acknowledgements}

One of the Authors, Tako, wishes to thank the late Professor Danji Nomura who was my supervisor in Doctoral Course in Food Science and Technology of Kyushu University for his encouraging me to talk many stories about Nobel Laureate Hans von Euler-Chelpin because Professor Nomura studied in Laboratory of Professor von Euler, University of Stockholm, Sweden in 1959-1960.

The Author has also heard lot about Emil Fischer, van't Hoff, Max Planck, Hermann Nernst and Svante Arrhenius 
because those Nobel Laureates were professors of Hans von Euler in Berlin, Gottingen and Stockholm Universities, Germany and Sweden. Professor van't Hoff is well known as a man who created stereo chemistry by finding out the carbon atom involves tetrahedral conformation, and relationship between stereo isomers and their optical activity. Professor Emil Fischer is also well known as a man who established stereo chemistry by elucidating chemical structure of D-glucose, D-galactose, D-mannose and D-fructose. Professor Nernst and Arrhenius discovered dissociation of electrolyte in water and third law of thermodynamics.

The Author was a lucky student because Professor Danji Nomura, Hans von Euler, Emil Fischer, van't Hoff, Max Planck, Hermann Nernst and Svante Arrhenius have led me on the road to the structure-function relationship of the polysaccharides when I was listening to the first movement of Piano Sonata No. 14 Op. 27-2 "Moon Light" composed by Ludwig van Beethoven on July 16 in 1973.

\section{References}

[1] Tako, M., Nakamura, S. Indicative evidence for a conformational transition in $\kappa$-carrageenan from studies of viscosity-shear rate dependence, Carbohydrate Research, 1986, Vol. 155, pp. 200-205.

[2] Tako, M., Nakamura, S. Synergistic interaction between kappa-carrageenan and locust-bean gum in aqueous media. Agricultural and Biological Chemistry, 1986, Vol. 50, pp. 2817-2822.

[3] Qi, Z.-Q., Tako, M., Toyama, S. Molecular origin for rheological characteristics of $\kappa$-carrageenan isolated from Hypnea charoides. Journal of Applied Glycoscience, 1998, Vol. 44, pp. 331-336.

[4] Tako, M., Nakamura, Kohda, Y. Indicative evidence for a conformational transition in 1-carrageenan. Carbohydrate Research, 1987, Vol. 161, pp. 247-253.

[5] Lin, L.-H., Tako, M., Hongo, F. Molecular origin for rheological characteristics of 1 -carrageenan isolated from Eucheuma serra, Food Science Technology Research, Vol. 7, pp. 176-180, 2001.

[6] Tako, M., Nakamura, S. Gelation mechanism of agarose, Carbohydrate Research, Vol. 180, pp. 277-283, 1980.

[7] Tako, M., Sakae, A., Nakamura, S. Rheological properties of gellan gum in aqueous media,"Agricultural and Biological Chemistry, Vol. 53, pp. 771-776, 1989.

[8] Tako, M., Hizukuri, S. Evidence for conformational transitions in amylose, Journal of Carbohydrate Chemistry, Vo. 14, pp. 613-622, 1995.

[9] Tako, M., Hanashiro, I. Evidence for a conformational transition in curdlan, Polymmer Gels and Networks, Vol. 5, pp. 241-250, 1997.

[10] Tako, M., Kohda, Y. Calcium induced association characteristics of alginate, Journal of Applied Glycoscience, Vol. 44, pp. 153-159, 1997.

[11] Teruya, T., Konishi, T., Tako, M. Rheological characteristics of alginate isolated from Nemacystus decipiens, Journal of Applied Glycoscience, Vol. 57, pp. 7-12, 2010.

[12] Tako, M., Hizukuri, S. Gelatinization mechanism of rice starch, Journal of Carbohydrate Chemistry, Vol. 18, pp. 573-584, 1999.

[13] Tako, M. Gelatinization characteristics of rice starch (Yukihikari), Journal of Applied Glycoscience, Vol. 47, pp. 187-192, 2000.

[14] Tako, M., Hizukuri, S. Retrogradation mechanism of rice starch, Cereal Chemistry, Vol. 77, pp. 473-477, 2000.

[15] Tako, M., Hizukuri, S. Gelatinization mechanism of potato starch, Carbohydrate Polymmers, Vol. 48, pp. 397-401, 2003.

[16] Tako, M., Tamaki, Y., Konishi, T., Shibanuma, K., Hanashiro, J., Takeda, Y. Gelatinization and retrogradation characteristics of wheat (Rosella) starch, Food Research Intternational, Vol. 41, pp. 797-802, 2008.

[17] Tako, M., Tamaki, Y., Konishi, T., Shibanuma, K., Hanashiro, I., Takeda, Y. Rheological characteristics of Halberd wheat starch, Starch/Stärke, Vol. 61, pp. 275-281, 2009.

[18] Tako, M., Tohma, S., Taira, T., Ishihara, M. Gelation mechanism of deacetylated rhamsan gum, Carbohydrate Polymers, Vol. 54, pp. 279-285, 2003.

[19] Tako, M., Teruya, T., Tamaki, Konishi, T. Molecular origin for rheological characteristics of native gellam gum, Colloid and Polymmer Science, Vol. 287, pp. 1445-1454, 2009.

[20] Tako, M., Asato, A., Nakamura, S. Rheological aspects for intermolecular interaction between xanthan and locust bean gum in aqueous media, Agricultural and Biological Chemistry, Vol. 48, no. 12, pp. 2995-3000, 1984.

[21] Tako, M., Nakamura, S. D-Mannose specific interaction between xanthan and D-galacto-D-mannan, FEBS Letters, Vol. 204, pp. 33-36, 1986.

[22] Tako, M. Synergistic interaction between deacylated xanthan and D-galacto-D-mannan, Journal of Carbohydrate Chemistry, Vol. 10, pp. 619-633, 1991.

[23] Tako, M. Binding sites for D-mannose-specific interaction between xanthan and galactomannan, and glucomannan, Colloids and Surfaces B Biointerfaces, Vol. 1, no. 1, pp. 125-131, 1993.

[24] Tako, M., Nakamura, S. Synergistic interaction between xanthan and guar gum, Carbohydrate Research, Vol. 138, pp. 207-213, 1985.

[25] Tako, M. Synergistic interaction between xanthan and tara-bean gum, Carbohydrate Polymers, Vol. 16, pp. 239-252, 1991.

[26] Pakdee, P., Tako, M., Kinjyo, K., Hongo, F., Yaga, S. Synergistic interaction between xanthan and galactomannan isolated from Leucaena leucosephala. Journal of Applied Glycoscience, Vol. 42, pp. 105-113, 1995.

[27] Tako, M., Tamaki, Y., Teruya, T. Cogelation mechanism of xanthan and galactomannan. Journal of Colloid and Polymer Science, Vol.288, pp.1161-1166, 2009.

[28] Tako, M. Synergistic interaction between xanthan and konjac glucomannan in aqueous media, Bioscience, Biotechnology, and Biochemistry, Vol. 56, pp. 1186-1192, 1993. 
[29] Tako, M., Kiriaki, M. Rheological properties of welan gum in aqueous media, Agricultural and Biological Chemistry, Vol. 54, no. 12, pp. 3079-3084, 1990.

[30] Tako, M. Molecular origin for thermal stability of rhamsan gum in aqueous media, Bioscience, Biotechnology, and Biochemistry, Vol. 57, pp. 1182-1184, 1993.

[31] Tako, M. Molecular origin for the thermal stability of S-657 polysaccharide produced by Xanthomonas ATCC 53159, Polymer Gels and Network, Vol. 2, pp. 358-371, 1994.

[32] Tako, M., Tamaki, H. Molecular origin for thermal stability of S-88 gum produced by Pseucomonas ATCC31554, Polymer Journal, Vol. 37, pp. 498-505, 2005.

[33] Tako, M., Kitajima, S.,Yogi, T., Onaga, M., Tamaki, Y. Uechi. Structure-function relationship of a gellan family of polysaccharide produced by Alcaligenes ATCC31853. Advances in Biological Chemistry, Vol. 6, pp. 55-69, 2016.

[34] Tako, M. Structural principles of polysaccharide gels, Journal of Appied. Glycoscience, Vol. 47, no. 1, pp. 49-53, 2000.

[35] Tako, M. The principle of polysaccharide gels, Advances in Bioscience and Biotehcnology, Vol. 6, pp. 22-35, 2016.

[36] Tako, M., Tamaki, Y., Teruya, T., Takeda, Y. The principles of starch gelatinization and retrogradation, Food Nutrition Sciences, Vol. 5, no. 2, pp. 280-291, 2014.

[37] Lahaye M. (1998) NMR spectroscopic characterization of oligosaccharides from two Ulva rigida ulvan samples (Ulvales, Chlorophyta) degraded by a lyase. Carbohydrate Research. 314, 1-12.

[38] Lahaye, M., Robic. A. Structure and functional properries of ulvan, a polysaccharide from green seaweeds, Biomacromolecules, 6, 1765-1774, 2007.
[39] Shao, P., Oin, M., Han, L., Sun, P. Rheology and characteristics of sulfated polysaccharide from Chlorophyte seaweeds Ulva faciata. Carbohydrate Polymers, 113, 365-372, 2014.

[40] Nakamura, M., Konishi, T., Hanashiro, I., Tako, M. Isolation and structural characterization of rhamnan sulfate isolated from commercially cultured Monostroma nitidum, Nippon Shokuhin Kagakukougaku Kaishi, Vol. 57, pp. 245-251, 2011.

[41] Dubois, M., Gilles, K. A., Hamilton, J. K., Rebers, P. A., Smith, F. Colorimetric method for determination of sugars and related substances, Analytical Chemistry, Vol. 28, pp. $350 \quad 356,1956$.

[42] Bitter, T., Nuir, H. M. A modified uronic acid carbazole reaction, Analytical Biochemistry, Vol. 203, pp. 330-334, 1962.

[43] Dodgson, K. S., Price, R. C., A note on the determination of the ester sulfate content of sulfated polysaccharides, Biochemical Journal, Vol. 84, pp. 106-110, 1962.

[44] Harris, J. In Rheology and non-Newtonian flow. Longman: New York, USA, 1977; pp. 28-33.

[45] Markovitz, H. A. A property of bessel functions and its application to the theory of two rheometers, Journal of Applied Physics, Vol. 23, pp. 1070-1077, 1952.

[46] Tako, M., Nagahama, T., Nomura, D. Flow characteristics of the viscous polysaccharide produced by Coryneform Bacteria Strain C-8. Nippon Nogeikagaku Kaishi, Vol. 51, pp. 397-402, 1977.

[47] Tako, M., Nagahama, T., Nomura, D. Non-Newtonian flow and dynamic viscoelasticity of xanthan gum. Nippon Nogeikagaku Kaishi. Vol. 51, pp. 513-518, 1977.

[48] Tako, M., Nakamura, S. Rheological properties of Ca salt of xanthan in aqueous media, Agricultural and Biological Chemistry, Vol. 51, pp. 2919-2923, 1987. 